\title{
LITERATURA DE CORDEL COMO ESTRATÉGIA EDUCATIVA PARA PREVENÇÃO DA DENGUE ${ }^{1}$
}

\author{
Paula Marciana Pinheiro de Oliveira², Jamile de Souza Pacheco Paiva ${ }^{3}$, Kariane Gomes Cezario ${ }^{4}$, Lorita \\ Marlena Freitag Pagliuca ${ }^{5}$
}

${ }^{1}$ Trabalho elaborado no Projeto Laboratório de Comunicação em Saúde, do Departamento de Enfermagem da Universidade Federal do Ceará (UFC), e financiado pelo Conselho Nacional de Desenvolvimento Científico e Tecnológico (CNPq), 2010.

${ }^{2}$ Doutoranda do Programa de Pós-Graduação em Enfermagem da UFC. Bolsista CNPq. Ceará, Brasil. E-mail: paulamarciana@ yahoo.com.br

${ }^{3}$ Enfermeira do Hospital Dr. Carlos Alberto Studart Gomes. Ceará, Brasil. E-mail: jamile_pacheco@yahoo.com.br

${ }^{4}$ Doutoranda do Programa de Pós-Graduação em Enfermagem da UFC. Bolsista da CAPES. Ceará, Brasil. E-mail: kariane_ gomes@yahoo.com.br

${ }^{5}$ Doutora em Enfermagem. Professora Titular do Departamento de Enfermagem da UFC. Pesquisadora do CNPq. Ceará, Brasil. E-mail: pagliuca@ufc.br

RESUMO: O objetivo do estudo foi analisar as mensagens transmitidas e a linguagem abordada em folhetos sobre a temática dengue. Estudo exploratório-descritivo, documental, precedido de busca sistemática de cordéis, entre abril e maio de 2010. Dos folhetos pesquisados, dois abordavam o tema. Com a Análise de Conteúdo construíram-se três categorias: Conhecendo a dengue, com características da doença em si e também dos seus sinais e sintomas; Prevenção da dengue, com ênfase nas formas de prevenção à proliferação do mosquito e sua eliminação; e Literatura de cordel como estratégia educativa, retratando como o cordel é um meio viável à prevenção da dengue. Os cordéis apresentaram conteúdo informativo satisfatório para produzir alerta favorável a medidas contra a dengue, aliando informações aos costumes culturais regionais.

DESCRITORES: Dengue. Literatura. Promoção da saúde. Prevenção primária.

\section{STRING LITERATURE AS AN EDUCATIONAL STRATEGY IN DENGUE PREVENTION}

\begin{abstract}
This study aimed to analyze the messages conveyed and discussed in Cordel literature, or string leaflets, on dengue. This exploratory-descriptive documentary research, preceded by a systematic search of string leaflets, was carried out between April and May of 2010. Two of the examined leaflets addressed the theme. Three categories arose from content analysis: Getting to know dengue, including characteristics of the disease itself and its signs and symptoms; Dengue prevention, emphasizing ways to prevent mosquito dissemination and elimination; and string literature as an educational strategy, outlining how it is a viable tool for dengue prevention. String leaflets present satisfactory information content which produces a favorable alert towards counter-dengue measures, linking information to regional cultural customs.
\end{abstract}

DESCRIPTORS: Dengue. Literature. Health promotion. Primary prevention

\section{LITERATURA DE CORDEL COMO ESTRATEGIA EDUCATIVA PARA PREVENCIÓN DEL DENGUE}

RESUMEN: La finalidad fue analizar los mensajes transmitidos y discutidos en los folletos del dengue tema. Estudio exploratoriodescriptivo, documental, precedido de búsqueda sistemática de cordeles, entre abril y mayo de 2010. De los pliegos investigados, dos trataban del tema. Con el Análisis de Contenido construyó tres categorías: Conociendo al dengue, con características de la enfermedad en sí y también de sus señales y síntomas; Prevención del dengue, con énfasis en las formas de prevención a la proliferación del mosquito y su eliminación; y Literatura de cordel como estrategia educativa, retratando como el cordel representa un medio viable para la prevención del dengue. Los cordeles mostraron contenido informativo satisfactorio para producir un alerta favorable a medidas contra el dengue, aliando informaciones a los costumbres culturales regionales.

DESCRIPTORES: Dengue. Literatura. Promoción de la salud. Prevención primaria 


\section{INTRODUÇÃO}

A poesia popular impressa, também denominada literatura de cordel, são folhetos escritos sob forma de versos rimados e seu sucesso deve-se a um conjunto de fatores, principalmente a relação com a oralidade mantida nas suas composições. ${ }^{1}$ Adquiridos esses cordéis, as pessoas reuniam-se para ler em grupos. Tais reuniões congregavam grande número de pessoas, na casa de vizinhos e familiares. Aqueles que possuíam maior diversidade e maior número de títulos em casa convidavam os demais para participar do momento de descontração. ${ }^{2}$

São denominados cordéis porque em Portugal, onde eram vendidos, ficavam expostos em barbantes, tipo corda. O apogeu deste meio de comunicacão no Nordeste predominou durante a política populista de Getúlio Vargas, nas décadas de 1940 e 1950, quando houve um maior número de publicacões. Embora a venda desses folhetos tenha alcançado recordes em apenas três meses, durante mais de vinte anos, deixou-se de reeditar muitos clássicos do cordel. Contudo, a partir de 2000, voltaram a ser publicados no seu formato tradicional. ${ }^{3}$

A literatura de cordel surgiu na Península Ibérica, e veio para o Nordeste do Brasil em fins do século XIX, onde se tornou conhecida e se desenvolveu. Foi trazida pelos colonizadores europeus, e expandiu-se no início do século XX, especificamente no Ceará. ${ }^{3}$

Em suas histórias escritas, de modo geral, os folhetos retratam disputas, vidas de personagens e pessoas que marcaram a história de cidades, assuntos diversos. Existem temáticas com enfoque também na área da saúde, dentre estas, amamentação, HIV/aids, diabetes, saúde da mulher. Assuntos nesta área são muito interessantes para serem retratados, pois representam meios de comunicacão passíveis de auxiliar na promoção da saúde, empoderando as pessoas a construírem autonomia e crescimento próprio.

Por ser uma das doenças com maior incidência no Brasil, a dengue é uma temática importante a ser abordada, porquanto seu conhecimento, sua identificação precoce, a tomada de decisão e implementação de medidas de maneira oportuna constituem ações primordiais para evitar óbitos. ${ }^{4}$

A infecção pelo vírus da dengue causa uma patologia de amplo espectro clínico, que pode ser de curso benigno ou grave, de acordo com a forma como se apresente: infecção inaparente, Dengue Clássica (DC) e Febre Hemorrágica da Dengue (FHD), ou Síndrome de Choque da Dengue (SCD). ${ }^{4}$
No Brasil, a dengue é hoje objeto da maior campanha de saúde pública. Com base nessa campanha, o controle é eficaz através de medidas preventivas relacionadas ao único vetor reconhecido como transmissor do vírus da dengue em nosso meio, o Aedes aegypti. Este mosquito está adaptado a se reproduzir em ambientes doméstico e peridoméstico, com a utilização de recipientes onde se armazena água potável e de recipientes descartáveis que acumulam água de chuvas, comumente encontrados nos lixos das cidades. A doença disseminou-se pelos 27 estados da federação, distribuída por 3.794 municípios e responsável por cerca de $60 \%$ das notificações nas Américas. ${ }^{5}$

Em 1981, os sorotipos 1 e 4 foram os primeiros isolados em uma epidemia de dengue ocorrida em Boa Vista, Estado de Roraima. Em 1990-1991, surgiu o sorotipo 2 e em 2001-2003, o sorotipo 3. No momento, os sorotipos 1, 2 e 3 circulam em 24 estados da federação simultaneamente. Desse modo contribuem para a incidência das formas graves da dengue (dengue hemorrágica e síndrome do choque da dengue) nas cidades onde se registraram epidemias sequenciais por pelo menos dois sorotipos diferentes. ${ }^{5}$

Atualmente a dengue é considerada um problema de saúde pública, pois gera gastos de milhões de dólares por ano. ${ }^{6}$ Aproximadamente três bilhões de pessoas estão expostos a contrair o vírus e são registrados, por ano, 50-100 milhões de casos de dengue clássica, cerca de 500 mil internações causadas por febre hemorrágica, podendo existir um nível de mortalidade de $5 \%{ }^{7}$

Nos anos de 2001 e 2005, o Brasil apresentou $56 \%$ dos casos de dengue notificados nas Américas. ${ }^{8}$ Em 2004, o aumento foi de aproximadamente $95 \%$ na média nacional, enquanto em 2005 registraram-se 241.796 casos de dengue clássica, pela forma hemorrágica, e 43 óbitos da doença. ${ }^{9}$

Nos últimos anos, a promoção da saúde tem seu foco na emancipação individual, a partir do conhecimento adquirido coletivamente. Diante disto, a intersetorialidade tem sido muito visada com esse intuito, pois os profissionais procuram estratégias que despertem uma melhor participação e discussão com a sociedade na busca de ações efetivas de saúde. Uma dessas estratégias éa literatura de cordel, a qual, por suas características, poderá contribuir na prevenção deste problema, por ser um meio que envolve a rima, versos, formas atrativas de exposição das informações, com vistas à educação em saúde. 
Em face do exposto e por se necessitar de um meio de comunicação capaz de despertar nas pessoas a consciência crítica sobre a prevenção do vírus da dengue, objetivou-se, neste estudo, analisar as mensagens transmitidas e a linguagem abordada em folhetos, sobre a temática da dengue.

\section{MATERIAIS E MÉTODOS}

Trata-se de um estudo descritivo, documental, exploratório e de caráter analítico. Na pesquisa descritiva, o autor observa, descreve e documenta os aspectos da situação, sem procurar necessariamente estabelecer uma relação causal entre as variáveis. A pesquisa exploratória investiga a natureza e os outros fatores relacionados. Também destina-se a desvendar as maneiras pelas quais um fenômeno se manifesta. ${ }^{10}$

O estudo se desenvolveu mediante a busca sistemática de folhetos de cordel disponíveis em cordões (varais) nas praças públicas da cidade de Fortaleza-CE e foi realizado nos meses de abril e maio de 2010. Como critério de seleção decidiu-se por temas que retratassem a temática de saúde. Cinco praças foram visitadas e em três destas localizaram-se cordéis que se adequavam ao tema proposto.

Optou-se pelo método de conteúdo para análise dos dados. ${ }^{11}$ Quanto aos procedimentos de análise, estes ocorreram em três momentos: a pré-análise, a exploração do material e o tratamento dos resultados, com a inferência e a interpretação, tendo como suporte a literatura sobre a dengue. A pré-análise caracteriza-se pela organização e escolha do material coletado com o objetivo de fundamentar a interpretação dos dados. Ainda nesta fase, faz-se a leitura dos folhetos, denominada "leitura flutuante", a preparação do material e a elaboração dos indicadores (temas). A exploração do material é a fase que demanda mais tempo, pois nela se procede às codificações nas quais o material (os dados) coletado é transformado em unidades de compreensão correspondentes ao conteúdo dos folhetos. Por codificação entende-se a escolha das unidades de registro (recorte), a seleção de regras de contagem (enumeração) e a escolha de categorias (classificação e agregação). ${ }^{11}$

Sendo assim, para análise do material, os dados foram codificados por temáticas e os mesmos discutidos conforme literatura científica pertinente à temática. No concernente ao tratamento dos resultados, consistiu nas inferências feitas sobre os dados, sendo sua interpretação alcançada por meio da relação entre as informações encontradas e a fundamentação teórica adotada.

\section{RESULTADOS E DISCUSSÃO}

Foram coletados 36 folhetos. Destes, 22 abordavam temas na saúde e, dentre estes, dois retratavam a temática da dengue. Estes folhetos são intitulados "Vamos eliminar o mosquito da dengue" e "Poeta e estudantes contra a dengue e raiva". O primeiro foi escrito por Chico Savino e o segundo, por Marcos Silva.

No artigo ora elaborado, baseado no referencial metodológico proposto, foram desenvolvidas três categorias, assim denominadas: (1) Conhecendo a dengue; (2) Prevenção da dengue; e (3) Literatura de cordel como estratégia educativa. A primeira categoria foi subdividida em três subcategorias: transmissão, sinais e sintomas e tratamento.

Ao se perceper a provável repercussão da dengue na população de um modo geral, constatou-se a importância do conhecimento de sua patologia, sinais e sintomas e tratamento. No quadro 1 apresenta-se a categoria Conhecendo a dengue. Apenas um cordelista, Marcos Silva, descreveu sobre estes aspectos.

Como apontado no quadro 1 , na subcategoria 1 , que retrata a transmissão da dengue, o Aedes aegypti é um mosquito, antropofílico, doméstico, com atividade e boa capacidade de adequação ao meio ambiente. ${ }^{12} \mathrm{~A}$ fêmea do mosquito no ambiente favorece a sobrevivência e reprodução do seu vetor. Isto condiciona a persistência e a progressão desta virose. ${ }^{13}$

Dentre os fatores específicos relacionados à procriação deste vetor e consequente transmissão do vírus, encontram-se os recipientes de caráter permanente, com maior destaque para caixas d'água, potes, latas, garrafas, vasos de plantas, pneus e tambores. Todos estes itens encontram-se principalmente nos grandes centros urbanos e favorecem a interação entre o mosquito, o arbovírus e o ser humano, ao acumularem água limpa e parada. ${ }^{14}$

No tocante às características e hábitos do Aedes aegypti, segundo se observa, este possui coloração preta ou "cor de café", listras brancas no tronco e nas patas e menos de um centímetro de comprimento. Habitualmente contamina os seres humanos nos horários matutinos e vespertinos e a fêmea possui a capacidade de realizar a oviposição durante a vida inteira, com uma postura de cerca de 150 a 200 ovos por vez. Quando infectada pelo arbovírus, existe quase $40 \%$ de probabilidade de ovos já nascerem infectados. ${ }^{15}$ 
Quadro 1 - Conhecendo a dengue. Fortaleza-CE, 2010

\begin{tabular}{|l|l|l|}
\hline \multicolumn{1}{|c|}{ Categoria 1: Conhecendo a dengue } \\
\hline \multicolumn{1}{|c|}{ Transmissão } & \multicolumn{1}{c|}{ Sinais e sintomas } & \multicolumn{1}{c|}{ Tratamento } \\
\hline Amigos de início & Os sintomas mais frequentes & Muito líquido e repouso \\
Da dengue eu vou falar & Que podem acontecer & Isso é fundamental \\
Quem transmite é um mosquito & É dor de cabeça, febre alta & Não tome acetil salicílico \\
Qualquer um pode pegar & Músculos e juntas faz doer & Como aspirina e melhoral \\
Aedes Aegypti é seu nome & Podendo em alguns casos & O AAS e o sonrisal \\
Não esqueça de gravar & O sangramento ocorrer & \\
Mas tem uma diferença & Também falta apetite & \\
Que está em suas patas & Surge manchas avermelhadas & \\
São listradas de branco & Coça e dói no corpo todo & \\
Esse fato nos retrata & Como quem tomou porrada & \\
Que podemos identificá-lo & É a "febre quebra ossos" & \\
Com inteligência nata & Que por muitos é chamada & \\
Ele se desenvolve & & \\
Em água limpa e parada & & \\
A fêmea põe seus ovos & & \\
Em água acumulada & & \\
Entre sete e dez dias & & \\
Começa sua jornada & & \\
\hline
\end{tabular}

Ainda no quadro 1, tem-se a subcategoria 2, os sinais e sintomas da dengue. A forma clássica desta doença é benigna e incapacitante. Quando acomete uma pessoa, esta permanece por no mínimo sete dias em repouso. Acarreta considerável comprometimento geral e consequente faltas ao trabalho e à escola, além dos custos da atenção clínica e laboratorial. ${ }^{12}$

Na dengue hemorrágica, os sintomas iniciais são os mesmos da dengue clássica, porém evoluem rapidamente para sintomas hemorrágicos de gravidade variável. O caso típico é caracterizado por febre alta e fenômenos hemorrágicos variáveis desde leves sangramentos gengivais a manifestações graves, como hemorragia gastrintestinal, intracraniana e derrames. Contudo, os casos mais severos podem levar o paciente a óbito em 12 a 24 horas e diferenciam-se pelos sinais de insuficiência circulatória e choque. Se a pessoa receber tratamento antichoque apropriado, recupera-se adequadamente. ${ }^{16}$

Em geral, a febre tem duração de quatro dias, e a cefaleia localiza-se frontalmente. As náuseas, vômitos e anorexia impedem uma dieta adequada, levando o paciente a um quadro de prostração. $\mathrm{O}$ paciente também pode apresentar exantema, a se manifestar sob duas formas: pruriginosa e não-pruriginosa, geralmente mais referido na fase de convalescência. O exantema pode aparecer precoce ou tardiamente. No primeiro caso, costuma ser fugaz, acometendo cabeça e tronco. No segundo caso, ocorre no período de remissão da febre, sendo difuso, maculopapuloso e mais acentuado na palma das mãos e planta dos pés. Isto leva a crer que foi a forma predominante. ${ }^{17}$

Na maioria das vezes, a doença não produz intercorrências sérias. Segundo determinado estudo, apenas $10,7 \%$ da população ficaram hospitalizados pelo período de um a dois dias. Estudo similar realizado em Natal também não encontrou complicações. Nesse caso, os sintomas mais frequentes foram prostração, febre, cefaleia e mialgias. ${ }^{12}$

Entretanto, diante de qualquer caso suspeito de dengue, deve-se procurar atendimento médico, pois quando tratada devidamente a doença não se agrava. Além disso, trata-se de uma doença de notificação compulsória. A possibilidade de que melhora com repouso, hidratação, analgésicos, antitérmicos e com a permanência no domicílio diminui a demanda dos serviços de saúde, mas não contribui para o controle do processo de endemização da dengue e outras doenças virais. Como observado, tais informações têm levado os pacientes, com outras infecções agudas, a não procurarem atendimento, colaborando assim para subnotificação da dengue, além de outras viroses que exigem um diagnóstico diferencial. ${ }^{12}$

Quanto ao tratamento, subcategoria 3, também descrita no quadro 1 , em virtude da inespecificidade desta doença, muitas vezes torna-se difícil diagnosticá-la precisamente. Então, as condutas terapêuticas visam minimizar possíveis complicações decorrentes de sua sintomatologia. A abordagem 
deverá contemplar a identificação da gravidade e do estadiamento da doença. Esta etapa deve ser precedida por anamnese, com ênfase na cronologia dos sinais e sintomas; exame físico, com avaliação de alterações na pele, hidratação, pressão arterial e realização da prova do laço. Além destes aspectos, o diagnóstico diferencial em relação a outras viroses e doenças exantemáticas é de extrema relevância. ${ }^{18}$

Em todos os casos, recomendam-se a hidratação oral específica, o uso de analgésicos, antitérmicos, antieméticos e antipruriginosos, quando indicados. Desaconselha-se, porém, o uso de salicilatos e anti-inflamatórios não-hormonais. Quando necessário, a hidratação parenteral prescrita é o tipo mais indicado de reposição de volume intravascular. Junto a estas prescrições, recomendam-se o repouso bem como o estímulo à alimentação saudável. ${ }^{18}$

$\mathrm{Na}$ categoria representada no quadro 2, constatou-se a importância da prevenção da dengue. Prevenir é tomar medidas com antecipação, preparar, avisar, acautelar-se.

\section{Quadro 2 - Prevenção da dengue. Fortaleza-CE, 2010}

\begin{tabular}{|c|c|}
\hline \multicolumn{2}{|c|}{ Categoria 2: Prevenção da dengue } \\
\hline Caixa d'água e cisterna & Encha tudo de areia \\
\hline Ou reservatório qualquer & Pra poder enfim enxugar \\
\hline Devem ser bem vedados & Até os pratos das plantas \\
\hline Esse cuidado requer & Pro mosquito não pousar \\
\hline Lona, plástica ou tela fina & E fazer sua grande festa \\
\hline Que no comércio tiver & $\begin{array}{l}\text { Por que assim o que resta } \\
\text { É ele se proliferar }\end{array}$ \\
\hline Tanques, tambores tinas & \\
\hline Ou depósitos semelhantes & Guarde todas as garrafas \\
\hline Requer outros cuidados & Na seguinte posição \\
\hline Que também são importantes & De cabeça para baixo \\
\hline Esvazie toda semana & Com muita convicção \\
\hline Mas faça limpeza antes & $\begin{array}{l}\text { Que vai mesmo combater } \\
\text { E evitar alguém morrer }\end{array}$ \\
\hline Para tirar os ovos & Com a cotaminação \\
\hline Que possam existir & Mantenham bem tampados \\
\hline Passe bucha ou esponja & Tudo se aborrecer \\
\hline Para o ovo sair & Tonéis e barris de água \\
\hline Fique ligado amigo & Não deixe nenhum encher \\
\hline Não vá no ponto dormir & $\begin{array}{l}\text { Por que na certa infelizmente } \\
\text { Esse fator faz a gente }\end{array}$ \\
\hline Latas e embalagens & Correr risco de morrer \\
\hline Nunca deixe jogadas & \\
\hline Ou expostas à chuva & Sempre mantenha a caixa d'ägua \\
\hline Com água acumulada & Com uma tampa adequada \\
\hline Garrafas quando vazias & Pra ela poder ficar \\
\hline Devem ficar viradas & $\begin{array}{l}\text { Sem risco e assim bem fechada } \\
\text { Para o bicho transmissor }\end{array}$ \\
\hline Amigo se você tem & Não encontre o seu valor \\
\hline Pneu velho no quintal & Se nela tiver entrada \\
\hline Se você encher de água & \\
\hline Sem dúvida será fatal & Não deixe a água da chuva \\
\hline Deixe-o em local seco & Na laje se acumular \\
\hline Longe da chuva afinal & Por que o perigo é grande \\
\hline & E difícil de se notar \\
\hline Se tiver planta em água & Por isso que é necessário \\
\hline Passe para a terra a tal & O agente ou o voluntário \\
\hline Ou troque a sua água & O prédio verificar \\
\hline Isso em tempo real & \\
\hline A cada quatro dias & \\
\hline Lave o vaso e o local & \\
\hline
\end{tabular}

Conforme se percebe nas descrições dos cordelistas, existe uma abordagem ampla quanto 
à prevenção da dengue, a depender fundamentalmente da redução populacional do vetor da doença no domicílio e peridomicílio. As larvas do mosquito depositam-se em recipientes que acumulam água limpa e passam a ser importantes focos para a proliferação do vetor da dengue. Assim, seu controle constitui-se no mais efetivo modo de reduzir sua reprodução e dispersão nos centros urbanos. ${ }^{19}$

De acordo com o constatado em estudo com 28 casos suspeitos de dengue, cerca de metade destas pessoas ainda não dispõe de caixa d'água ou, quando a tem, esta não se encontra em perfeitas condições. As pessoas desprovidas de caixa d'água utilizavam-se de tonéis ou similares. Neste mesmo estudo, foram encontrados outros reservatórios, também envolvidos direta ou indiretamente com o surgimento da dengue, dentre estes: material de construção (telhas), planta aquática, pneus empilhados, garrafas plásticas e entulho. ${ }^{12}$

Segundo divulgado, as condições climáticas influenciam na incidência de casos de dengue, em decorrência do aumento da temperatura, da pluviosidade e da umidade do ar, por favorecer o aumento do número de criadouros disponíveis e também o desenvolvimento do mosquito. ${ }^{20}$ Esta patologia tem acometido indivíduos de ambos os sexos, porém há registro de maior incidência em mulheres do que em homens, assim como há um maior número de casos em pessoas com faixas etárias mais elevadas. ${ }^{21}$
Inúmeros são os fatores condicionantes para a reprodução e disseminação do Aedes aegypti. Por exemplo, o intenso fluxo rural-urbano e o consequente aumento populacional nas médias e grandes cidades motivaram o surgimento de uma infra-estrutura urbana deficitária. Além disso, o abastecimento de água, condições insatisfatórias de habitação e de saneamento básico e o acelerado processo industrial também contribuem para esse fenômeno. De modo geral, embalagens de plástico, alumínio, vidro ou isopor não são devidamente acondicionados após sua utilização, e é cada vez maior o número de pneus dispostos inadequadamente no meio ambiente. ${ }^{17}$

Apesar da população muitas vezes contribuir para a prevenção, algumas limitações ainda desencadeiam a expansão da dengue, sobretudo no combate ao vetor. Embora as atividades de vigilância sanitária sejam eficazes, no âmbito municipal necessitam de legislação de apoio e de práticas de fiscalização, com vistas à eliminação dos criadouros em pontos considerados estratégicos, como borracharias, cemitérios, depósitos de ferro velho, terrenos baldios descuidados e caixas d'água domiciliares descobertas. ${ }^{19}$

O quadro a seguir retrata sobre a importância da utilização da literatura de cordel como estratégia educativa. Ressalta de forma lúdica a dengue, que pode ser evitada pela população esclarecida.

\section{Quadro 3 - Literatura de cordel como estratégia educativa. Fortaleza-CE, 2010}

\begin{tabular}{|l|ll|}
\hline \multicolumn{2}{|c|}{ Categoria 3: Literatura de cordel como estratégia educativa } \\
\hline O poeta está querendo & Faça e cuide da limpeza & Não brinque com tal problema \\
Passar informação & Ao redor da moradia & Nem deixe material \\
Para que os alunos & Só desse jeito teremos & Exposto para mosquito \\
Tenham participação & A humanidade sadia & Por que de fato é fatal \\
Junto à comunidade & Com o seu sangue bem forte & Na chuva principalmente \\
Dando orientação & Sem ter receio da morte & Faça então rapidamente \\
& E livre da epidemia & O que é tudo normal \\
Há tempos esse poeta & & \\
Muito vem se empenhando & Mas para isso é preciso & É através de tudo isso \\
Usando todos os meios & Todo mundo se unir & Que você fica doente \\
O aluno orientando & Ninguém deixar o mosquito & Tome então esses cuidados \\
Fazendo muitas campanhas & Dentro de casa dormir & Com muita fé e urgente \\
E até dramatizando & E na mesa onde eu janto & Faça tudo com prazer \\
Nas ruas e nas escolas & Ou mesmo em outro canto & Pro seu vizinho dizer \\
Também dá o seu recado & Ele pode progredir & Que vocé é consciente \\
Vai em saral literário & & \\
O assunto é enfocado & & \\
É intenção do poeta & & \\
Deixar o aluno informado & & \\
\hline
\end{tabular}


Em todo aspecto de interatividade, as pessoas envolvidas precisam ter habilidade em se comunicar, pois isto permitirá enriquecer seus conhecimentos, identificar e obter satisfação das necessidades dos indivíduos, como também transmitir sentimentos e pensamentos, interagir, esclarecer e conhecer as opiniões e os sentimentos dos outros. ${ }^{22}$

A literatura de cordel tem-se apresentado como estratégia interessante de comunicação, sobretudo porque suas rimas e versos atraem a atenção das pessoas ao repassar informações em saúde de forma lúdica.

Estudos de análise de cordéis constataram a importância destes como poderosos instrumentos de estratégia educativa, em virtude do seu custo ser mínimo, da linguagem ser acessível e da sua mensagem ser facilmente compreendida pela população em geral. ${ }^{23-24}$

Segundo estudo realizado em Teresina, no Estado do Piauí, percebe-se ainda uma grande lacuna no conhecimento da população em relação aos aspectos favorecedores da presença do mosquito da dengue. Constatou-se esse resultado por meio de inquérito domiciliar e pelos tipos de depósitos encontrados. ${ }^{12}$

Assim, é imprescindível os profissionais desenvolverem habilidades comunicacionais e estratégias inovadoras de comunicação, na perspectiva de desencadear relações interpessoais com qualidade. Os profissionais de saúde interagem cotidianamente em seu trabalho, vivenciam uma relação com pessoas únicas, em contextos diferentes, carentes de alguém que as cuide e trate, isto é, que satisfaçam suas demandas. ${ }^{22}$ Neste contexto, os folhetos de cordel incentivam e auxiliam os profissionais na educação em saúde, no intuito de promover e educar as pessoas sob seus cuidados.

Outro aspecto a tornar relevante a parceria e atuação dos profissionais de saúde junto aos cordelistas é a oportunidade de colaborar no fornecimento de informações em saúde da maneira mais precisa. Apesar de abordarem com criatividade e eficiência a problemática da dengue e seus variados aspectos, verificam-se alguns erros, como relatou um cordelista sobre a existência de vacina contra a dengue. Esta constatação torna ainda mais necessária a parceria entre os profissionais da área da saúde e estes artistas populares. Dessa forma, poderá se propiciar o fornecimento de informações precisas e seguras, através de um meio de comu- nicação acessível e regionalizado, a exemplo da literatura de cordel.

\section{CONSIDERAÇÕES FINAIS}

Como observado, os cordelistas, por meio de sua arte, abordaram a dengue quanto a transmissão, sintomatologia, tratamento e prevenção de maneira criativa e eficiente, de acordo com uma proposta regionalizada de intervenção e promoção da saúde. Acredita-se, portanto, que a literatura de cordel é um excelente meio comunicativo de educação em saúde, pois com a sua rima e versificação consegue atrair e conquistar o público leitor na apreensão das informações.

A dengue é doença atual e possível de prevenção, por isso deve ser evitada. É importante que pesquisadores identifiquem a causa dos elevados índices e encontrem estratégias para preveni-las junto à população. Uma destas estratégias pode ser a literatura de cordel. Tal meio informativo pode ser também construído por profissionais de saúde. Estes como agentes educadores podem se interessar pela construção e/ou pela utilização do cordel e, então, trabalhar juntamente com poetas na sua elaboração. É uma maneira de aprender a recitar e cantarolar a ser usada nas palestras e em momentos educativos para o aprendizado e a distração.

$\mathrm{Na}$ cidade de Fortaleza, a literatura de cordel é encontrada em praças e em feiras de livro. É muito adotada em escolas e universidades, tem preço acessível e, de maneira geral, cativa crianças, adultos e idosos. Em face de todas as vantagens mencionadas, deve-se incentivar sua prática na saúde. Esta, com certeza, é uma recomendável estratégia.

Destaca-se que Destaca-se que a literatura de cordel é estratégia utilizada não só na saúde como também nas outras ciências. Como referido, pode ser usada para o ensino infantil e adulto e por ter seu preço acessível pode ser disseminada nas várias classes sociais. Na saúde, pode despertar o interesse de pacientes e clientes na mudança de atitude e comportamento, pois, em decorrência da sua linguagem compreensível e meio lúdico, esclarece melhor o leitor.

\section{AGRADECIMENTO}

Agradecemos ao Conselho Nacional de Desenvolvimento Científico e Tecnológico (CNPq) pelo apoio financeiro a este estudo. 


\section{REFERÊNCIAS}

1. Abreu M. "Então se forma a história bonita" relações entre folhetos de cordel e literatura erudita. Horiz Antropol. 2004 Jul-Dez; 10(22):199-218.

2. Galvão AMO. Oralidade, memorização e a mediação do outro: práticas de letramento entre sujeitos com baixos níveis de escolarização - o caso do cordel (1930-1950). Educ Soc. 2002 Dez; 23(81):115-42.

3. Lima AV. Acorda cordel na sala de aula. Fortaleza (CE): Tupynamquim; 2006.

4. Ministério da Saúde (BR), Secretaria de Vigilância em Saúde. Dengue: manual de enfermagem - adulto e criança. Brasília (DF): MS; 2008.

5. Câmara FP, Theophilo RLG, Santos GT, Pereira SRFG, Câmara DCP, Matos RRC. Estudo retrospectivo (histórico) da dengue no Brasil: características regionais e dinâmicas. Rev Soc Bras Med Trop. 2007 Mar-Abr; 40(2):192-6.

6. Organização Mundial da Saúde. Dengue hemorrágica: diagnóstico, tratamento, prevenção e controle. $2^{\mathrm{a}}$ ed. São Paulo (SP): OMS; 2001.

7. Barcelos C, Bastos FI. Geoprocessamento, ambiente e saúde: uma união possível? Cad Saúde Pública. 1996 Jul-Set; 12(3):389-97.

8. Bartley LM, Carabin H, Vinh Chau N, Ho V, Luxemburger C, Hien TT, et al. Assessment of the factors associated with flavirus eroprevalence in a population in Southern Vietnam. Epidemiol Infect. 2002 Apr; 128(2):213-20.

9. Braga C, Ximenes RAA, Albuquerque MFPM, Souza WV, Miranda J, Brayner F, Alves L, et al. Avaliação de indicador sócio-ambiental utilizado no rastreamento de áreas de transmissão de filariose linfática em espaços urbanos. Cad Saúde Pública. 2001 Set-Out; 17(5):1211-8.

10. Polit DF, Beck CT, Hungler BP. Fundamentos de pesquisa em enfermagem. $5^{\text {a }}$ ed. São Paulo (SP): Artmed; 2004.

11. Bardin L. Análise de conteúdo. Lisboa (PT): Edições 70; 2004.

12. Ribeiro PC, Sousa DC, Araújo TME. Perfil clínicoepidemiológico dos casos suspeitos de dengue em um bairro da zona sul de Teresina, PI, Brasil. Rev Bras Enferm. 2008 Mar-Abr; 61(2):227-32.
13. Câmara FP, Gomes AF, Santos GT, Câmara DCP. Clima e epidemias de dengue no Estado do Rio de Janeiro. Rev Soc Bras Med Trop. 2009 Mar-Abr; 42(2):137-40.

14. Forattini OP, Brito M. Reservatórios domiciliares de água e controle do Aedes aegypti. Rev Saúde Pública. 2003 Out; 37(5):676-7.

15. Ministério da Saúde [página na Internet] Brasil unido contra a dengue.. Brasília (DF): MS; 2009. [acesso 2009 Jun 15]. Disponível em: http://www. combatadengue.com.br

16. Secretaria Municipal de Saúde de Fortaleza, Prefeitura Municipal de Fortaleza. Boletim de saúde de Fortaleza. Fortaleza (CE): Secretaria Municipal de Saúde de Fortaleza; 2003.

17. Chiaravalloti VB, Favaro EA, Ferreira AC, Chiaravalloti Neto F, Mondini A, Dibo MR, et al. Atividades de controle do dengue na visão de seus agentes e da população atendida, São José do Rio Preto, São Paulo, Brasil. Cad Saúde Pública 2005 Jul-Ago; 21(4):1142-52.

18. Ministério da Saúde (BR), Secretaria de Vigilância em Saúde. Doenças infecciosas e parasitárias: guia de bolso. Brasília (DF): MS; 2005.

19. Corrêa PRL, França E, Bogutchi TF. Infestação pelo Aedes aegypti e ocorrência da dengue em Belo Horizonte, Minas Gerais. Rev Saude Pública. 2005 Jan;39(1):33-40.

20. Depradine CA, Lovell EH. Climatological variables and the incidence of dengue fever in Barbados. Int $J$ Environ Health Res. 2004 Dec ;14(6):429-41.

21. Gonçalves Neto VS, Rebêllo JMM. Aspectos epidemiológicos do dengue no município de São Luís, Maranhão, Brasil, 1997-2002. Cad Saúde Pública. 2004 Set-Out; 20(5):1424-31.

22. Pereira MAG. Má notícia em saúde: um olhar sobre as representações dos profissionais de saúde e cidadãos. Texto Contexto Enferm. 2005 Jan-Mar; 14(1):33-7.

23. Pagliuca LMF, Oliveira PMP, Rebouças CBA, Galvão MTG. Literatura de cordel: veículo de comunicação e educação em saúde. Texto Contexto Enferm. 2007 Out-Dez; 16(4):662-70.

24. Oliveira PMP, Rebouças CBA, Pagliuca LMF. Literatura de cordel como meio de promoção para o aleitamento materno. Esc Anna Nery Rev Enferm. 2008 Jun; 12(2):217-23. 